\title{
Co-Relation of 24 Hours Proteinuria And Left Ventricular Hypertrophy in Hypertensive Patients.
}

\author{
*Swapnil Chillawar,*Anuj Verma,**Sourya Acharya,*Pritam Kitey \\ *Asst. Professor, **Professor \\ Department Of Medicine, Jnmc, Dmimsu, Wardha, Maharashtra, India.
}

\begin{abstract}
Introduction: Hypertension is common disorder and leading cause of morbidity and mortality worldwide. Proteinuria has recently been identified as a cardiovascular risk marker in hypertensive patients. In this view left ventricular hypertrophy was studied with reference to hypertension and 24 hours proteinuria. Aims: To study left ventricular hypertrophy, 24 hours proteinuria and their co-relation in hypertensive subjects. Material and methods: The study was cross sectional type including 100 hypertensive subjects attending medicine department. The hypertensives with renal disease, ischaemic heart disease excluded from the study. Esbach's method to estimate 24 hour urine protein was used. Left ventricular hypertrophy $(L V H)$ was determined by 2-D echo using Devereux formula. Statistical analysis was done.Result: Mean Proteinuria for the duration of hypertension $\leq 5$ years was $0.27 \pm 0.13$ and for the duration of $>5$ years it was $0.44 \pm 0.14(z-$ value $=6.04, p$-value $=0.000)$. Mean LVH for the duration of hypertension $\leq 5 \mathrm{yr}$ was $118.55 \pm 31.81$ and for the duration of $>5$ years it was $231.74 \pm 53.71(\mathrm{z}$-value $=3.87$, -value $=0.000)$. Significant positive co-relation was found between proteinuria and $\mathrm{LVH}(r=0.350$, $p$-value $=0.000$ and Mean $\pm 2 S D$ of correlation of 0.012 to 0.392$)$ which means that as LVH increases proteinuria also increases significantly.

Conclusion: Hypertensive subjects develop proteinuria. As duration of hypertension increases, left ventricular hypertrophy and proteinuria also increases.
\end{abstract}

Keywords: Hypertension, left ventricular hypertrophy,proteinuria, cross-sectional

\section{Introduction}

Hypertension is a common disorder and leading cause of morbidity and mortality worldwide. ${ }^{(1)}$ It represents the single greatest preventable cause of death in humans and one of the most important modifiable risk factors for cardiovascular diseases. ${ }^{(2)}$ Recent reports indicate that nearly 1 billion adults (more than a quarter of the world's population) had hypertension in 2000, and this is predicted to increase to 1.56 billion by $2025 .{ }^{(3)}$ Hypertension is an important public health challenge in both economically developing and developed countries. $^{(4)}$ The standard definition of hypertension as blood pressure(BP) $>140 / 90 \mathrm{~mm} \mathrm{Hg}$ is based on the observation that the risk of CVD increases sharply above this level. However, recent data have shown that an increased risk of CVD is present in persons with BP levels as low as 115/75 $\mathrm{mm} \mathrm{Hg}$ and CVD risk doubles for each increment of 20/10 mmHg. The higher the BP, the greater the chance of heart attack, HF, stroke, and kidney diseases. ${ }^{(5)(6)}$

From another perspective, hypertension may be categorised as either essential or secondary. Changes in lifestyle and diet habits following urbanization are indeed greatly contributing to increased obesity, diabetes and dyslipidemia. Likewise, increased salt and alcohol intake in urban areas are the major risk factors for high blood pressure (BP). These global changes are now expected to increase also the potential health burden of kidney damage. ${ }^{(7)}$

In particular, the presence and degree of subclinical target organ damage namely left ventricular hypertrophy, carotid atherosclerosis, and renal dysfunction should be carefully searched for. The prevalence of microalbuminuria in untreated hypertensive patients ranges from 20 to $40 \%$ according to method used. Left ventricular hypertrophy is an independent predictor of adverse prognosis and is related to albumin excretion independent of age, blood pressure, diabetes, race, serum creatinine level, or smoking; these associations suggest parallel cardiac damage and increased renal albumin excretion rate. The patients with left ventricular hypertrophy, especially the concentric type, show a higher risk of developing a coronary event or a stroke as compared with those with normal left ventricular geometry. ${ }^{(8)}$

Left ventricular hypertrophy (LVH), which is the primary cardiac manifestation of hypertension, is a potent predictor of fatal and non-fatal cardiovascular (CV) events. ${ }^{(9)}$ Left ventricular hypertrophy is associated with microalbuminuria in patients with essential hypertension. ${ }^{(8)}$ Proteinuria has recently been identified as a CV risk marker in hypertensive patients. Whether LVH is the link between proteinuria and CV events is still a matter of debate. However, the Joint National Committee on Prevention, Detection, Evaluation, and Treatment of High Blood Pressure (JNC) VII advocates more aggressive treatment of hypertension in patients with proteinuria and LVH. The association between proteinuria and left ventricular (LV) mass has been 
inconsistent. ${ }^{(9)}$ Therefore, we sought to determine the relationship between 24 hour urine protein excretion and LV mass in hypertensive individuals with normal renal function.

\section{Aim And Objectives}

1) To study left ventricular hypertrophy in hypertensive subjects.

2) To study 24 hours proteinuria estimation in hypertensive subjects.

3) Correlation of left ventricular hypertrophy and 24 hours proteinuria in hypertensive subjects.

\section{Material And Methods}

The study was cross sectional observational type and had been approved by Institutional ethical committee. The study had been conducted in Medicine department of Acharya Vinobha Bhave Rural Hospital (A.V.B.R.H), a rural tertiary hospital of rural central India over a period of two years from August 2012 to July 2014.

\section{Sample Size}

100 hypertensive patients above 20 years were taken into consideration from medicine department. Informed consent was taken by every patient under study.

\section{Inclusion Criteria}

- 100 hypertensive cases selected on the basis of JNC VII classification of blood pressure for adult age > 18 years.

\section{Exclusion Criteria}

- Patients of diabetes mellitus, chronic renal disease, coronary artery disease, nephrotic syndrome, glomerulonephritis, urinary tract infections.

- Patients on drug causing proteinuria such as heavy metals, NSAID are excluded.

- Patient with acute febrile illness

Selected subjects to be included in the study were examined clinically. History of previous hypertension, cerebrovascular episode, and renal disease was sought. ECG, 2D echo, fundus examination, haemoglobin estimation, blood sugar examination, lipid profile, urine albumin, 24 hour proteinuria and serum creatinine estimation was done. Anthropometric measurements were carried out first, and then 24 hour proteinuria estimation followed by echocardiographic evaluation was carried out for LV mass index.

The height $(\mathrm{cm})$ and weight $(\mathrm{kg})$ was measured. The body surface area was calculated using mostellar formula and body mass index was estimated.

Mostellar formula ${ }^{(10)} \mathrm{BSA}\left(\mathrm{m}^{2}\right)=([\operatorname{Height}(\mathrm{cm}) \times \text { Weight }(\mathrm{kg})] / 3600)^{1 / 2}$

$\mathrm{BMI}=\operatorname{Mass}(\mathrm{Kg}) /\left[\right.$ height $\left.\left(\mathrm{m}^{2}\right)\right]$

Blood pressure estimation: SBP and DBP were measured using a mercury column sphygmomanometer. BP was measured twice in sitting position, and the average of the measurement was recorded. Patients are classified for hypertension according to JNC-7criteria. ${ }^{(5)(6)}$

24 Hour proteinuria estimation: 24 hour urine sample is collected for estimation of proteinuria by esbach's reagent. Normal range less than $150 \mathrm{mg} / 24$ hours. ${ }^{(11)}$

\section{Echocardiographic assessment:}

- 2D ECHO examination was carried out by Philips HD 11 XE Machine with a multifrequency phased Array Probe (2-4 MHZ)

- In M-mode and 2D mode, all measurements were made according to ASE conventions. ${ }^{(12)}$ For each variable, the mean of three different measurements was calculated.

- The normal values of LVMI considered are less than $103 \mathrm{gm} / \mathrm{m}^{2}\left(<103 \mathrm{gm} / \mathrm{m}^{2}\right)$ in males and less than $89 \mathrm{gm} / \mathrm{m}^{2}\left(<89 \mathrm{gm} / \mathrm{m}^{2}\right)$ in females. The patient was said to have increased LVMI when LVMI is more than $102 \mathrm{gm} / \mathrm{m}^{2}\left(>102 \mathrm{gm} / \mathrm{m}^{2}\right)$ in males and more than $88 \mathrm{gm} / \mathrm{m}^{2}\left(>88 \mathrm{gm} / \mathrm{m}^{2}\right)$ in females. ${ }^{(13)}$

Calculation of LVMI: The left ventricular mass index was calculated in all cases using modified Devereux formula, all the measurements were taken in centimetre $(\mathrm{cm})$ and left ventricular mass index was calculated in $\mathrm{gm} / \mathrm{m}^{2}$ per body surface area. ${ }^{(12)}$

\section{The formula included:-}

- $\quad \operatorname{LVMI}\left(\mathrm{gm} / \mathrm{m}^{2}\right)=\left\{0.8\left(1.04\left[\mathrm{IVSTD}+\mathrm{LVIDD}+\mathrm{PWTD}^{3}-\mathrm{LVIDD}^{3}\right\}+0.6\right)\right\}$ 
Body Surface Area

- LVMI: Left Ventricular Mass Index

- LVIDD: Left Ventricular Internal Diameter in Diastole

- PWTD: Posterior Wall Thickness In Diastole

- IVSTD: Interventricular Septum Thickness in Diastole.

\section{Statistical Analysis}

Statistical analysis was done by using descriptive and inferential statistics using z-test for difference between two means, chi square test, Pearson's correlation coefficient, multiple logistic regression and one way ANOVA. The software used in the analysis were SPSS 17.0 and Graph Pad 5.0 version and $\mathrm{p}<0.05$ is considered as level of significance $(\mathrm{p}<0.05)$.

\section{Observations And Results}

Table 1: Mean Parameters in patients with LVH versus without LVH

\begin{tabular}{|c|c|c|c|c|}
\hline Parameters & $\begin{array}{l}\text { LVH Present } \\
\text { (Echo) }\end{array}$ & $\begin{array}{l}\text { LVH Absent } \\
\text { (Echo) }\end{array}$ & z-value & p-value \\
\hline Gender (M/F) & $\begin{array}{l}38(38 \%) / \\
47(47 \%)\end{array}$ & $\begin{array}{l}11(11 \%) / \\
4(4 \%)\end{array}$ & 4.18 & $\begin{array}{l}0.041 \\
\mathrm{~s}, \mathrm{p}<0.05\end{array}$ \\
\hline Age(yrs) & $61.76 \pm 10.97$ & $65.71 \pm 12.47$ & 0.91 & $0.36 \mathrm{NS}, \mathrm{p}>0.05$ \\
\hline Weight(kg) & $61.98 \pm 7.36$ & $60.53 \pm 6.82$ & 0.71 & $0.47 \mathrm{NS}, \mathrm{p}>0.05$ \\
\hline $\mathrm{BMI}(\mathrm{kg} / \mathrm{m} 2)$ & $23.67 \pm 2.95$ & $23.35 \pm 2.30$ & 0.40 & $0.68 \mathrm{NS}, \mathrm{p}>0.05$ \\
\hline BSA & $1.62 \pm 0.12$ & $1.62 \pm 0.11$ & 0.05 & $0.95 \mathrm{NS}, \mathrm{p}>0.05$ \\
\hline SBP & $166.76 \pm 16.28$ & $155.20 \pm 15.52$ & 2.55 & $0.012 \mathrm{~S}, \mathrm{p}<0.05$ \\
\hline$\overline{\mathrm{DBP}}$ & $96.98 \pm 6.50$ & $91.06 \pm 8.10$ & 3.12 & $0.002 \mathrm{~S}, \mathrm{p}<0.05$ \\
\hline Sr. Creatinine & $1.08 \pm 0.34$ & $1.09 \pm 0.39$ & 0.03 & $0.96 \mathrm{NS}, \mathrm{p}>0.05$ \\
\hline $\begin{array}{ll}24 & \text { hour } \\
\text { proteinuria } & \\
\text { gm/day } & \\
\end{array}$ & $0.37 \pm 0.15$ & p. $27 \pm 0.19$ & 2.26 & $0.026 \mathrm{~S}, \mathrm{p}<0.05$ \\
\hline $\begin{array}{l}\text { Retinopathy } \\
\text { (Grade } \\
\text { 1/Grade2) }\end{array}$ & $38 \% / 47 \%$ & $10 \% / 5 \%$ & 2.46 & $0.11 \mathrm{NS}, \mathrm{p}>0.05$ \\
\hline
\end{tabular}

$38(38 \%)$ male and $47(47 \%)$ female patients had $\mathrm{LVH}$ and $11(11 \%)$ male and $4(4 \%)$ female were without LVH. Mean age and weight of patients with LVH was $61.76 \pm 10.97$ and $61.98 \pm 7.36$ respectively and those without LVH was $65.71 \pm 12.47$ and $60.53 \pm 6.82$ respectively. Mean BMI and BSA of patients with LVH was $23.67 \pm 2.95$ and1.62 \pm 0.12 respectively and that without LVH was $23.35 \pm 2.30$ and $1.62 \pm 0.11$ respectively.

Average systolic blood pressure and mean diastolic pressure for patients with LVH was $166.76 \pm 16.28$ and $96.98 \pm 6.50$ respectively and that without LVH was $155.20 \pm 15.52$ and $91.06 \pm 8.10$ respectively.

Mean Sr. creatinine level and mean 24 hours proteinuria for patients with LVH was $1.08 \pm 0.34$ and0.37 \pm 0.15 respectively and for that without $\mathrm{LVH}$ was $1.09 \pm 0.39$ and $0.27 \pm 0.19$ respectively. Grade 1 retinopathy was present in $38 \%$ patients with $\mathrm{LVH}$ and grade 2 was present in $47 \%$ patients with $\mathrm{LVH}$.

Table 2: Comparison of proteinuria and LVH with duration of Hypertension

\begin{tabular}{|l|l|l|l|l|}
\hline Duration & $\square 5 \mathrm{yr}$ & $\mathbf{5} \mathrm{yr}$ & & \\
Hypertension & $(\mathrm{n}=51)$ & $(\mathrm{n}=49)$ & & -v-value \\
\hline
\end{tabular}




\begin{tabular}{|l|l|l|l|l|} 
Proteinuria & $0.27 \pm 0.13$ & $0.44 \pm 0.14$ & & 0.000 \\
& $(\mathrm{n}=45)$ & $(\mathrm{n}=48)$ & 6.04 & $\mathrm{~S}, \mathrm{p}<0.05$ \\
\hline LVH & $\begin{array}{l}118.55 \pm 31.8 \\
1\end{array}$ & $\begin{array}{l}141.12 \pm 29.98 \\
(\mathrm{n}=40)\end{array}$ & 3.64 & 0.000 \\
& & & $\mathrm{~S}, \mathrm{p}<0.05$ \\
\hline
\end{tabular}

Mean proteinuria for the duration of hypertension $\leq 5$ years was $0.27 \pm 0.13$ and for the duration of $>5$ years it was $0.44 \pm 0.14$ ( $\mathrm{z}$-value $=6.04, \mathrm{p}$-value $=0.000)$. Mean $\mathrm{LVH}$ for the duration of hypertension $\leq 5$ years was $118.55 \pm 31.81$ and for the duration of $>5$ years it was $231.74 \pm 53.71$ ( $\mathrm{z}$-value $=3.87$, $\mathrm{p}$-value $=0.000$ ).

Table 3: Correlation of proteinuria with LVH

\begin{tabular}{|l|l|l|l|l|}
\hline & LVH & Percentage (\%) & \$2-value & Correlation 'r \\
\hline Proteinuria+ & 82 & $88.17 \%$ & & \\
$(\mathrm{n}=93)$ & & & 5.22 & 0.350 \\
\hline Proteinuria- & & $42.85 \%$ & $\mathrm{p}=0.022, \mathrm{~S}, \mathrm{p}<0.05$ & $\mathrm{p}=0.000, \mathrm{~S}$ \\
$(\mathrm{n}=7)$ & & & & \\
\hline
\end{tabular}

Significant positive correlation was found between proteinuria and $\operatorname{LVH}(\mathrm{r}=0.350$, $\mathrm{p}$-value $=0.000$ and Mean \pm 2 SD of correlation of 0.012 to 0.392 ) which means that as LVH increases proteinuria also increases significantly.

Table 4: Correlation of LV Geometry and LVH

\begin{tabular}{|l|l|l|l|l|}
\hline LV Geometry & LVH & LVH & z-value & p-value \\
& Present & Absent & & \\
\hline LVIDD cm & $45.14 \pm 5.06$ & $36.86 \pm 4.56$ & 6.36 & $0.000 \mathrm{~S}, \mathrm{p}<0.05$ \\
\hline PWTD cm & $12.91 \pm 1.54$ & $8.85 \pm 0.69$ & 6.45 & $0.000 \mathrm{~S}, \mathrm{p}<0.05$ \\
\hline IVSTD cm & $12.84 \pm 1.52$ & $9.14 \pm 0.89$ & 5.94 & $0.000 \mathrm{~S}, \mathrm{p}<0.05$ \\
\hline LVM gm & $224.88 \pm 47.41$ & $133.63 \pm 26.66$ & 10.62 & $0.000 \mathrm{~S}, \mathrm{p}<0.05$ \\
\hline LVMI gm/m2 & $138.06 \pm 27.52$ & $81.74 \pm 13.08$ & 12.49 & $0.000 \mathrm{~S}, \mathrm{p}<0.05$ \\
\hline
\end{tabular}

Mean LVIDD for patients with LVH was 45.14 \pm 5.06 and that for without LVH was $36.86 \pm 4.56$ ( $\mathrm{z}=6.36$, p-value=0.000). Mean PWTD for patients with LVH was $12.91 \pm 1.54$ and for without LVH was $8.85 \pm 0.69(\mathrm{z}=6.45, \mathrm{p}$-value=0.000). Mean IVSTD for patients with LVH was $12.84 \pm 1.52$ and for without LVH was 9.14 \pm 0.89 ( $\mathrm{z}=5.94$, p-value=0.000). Mean LVM for LVH positive patients was $224.88 \pm 47.41$ and for LVH negative patients it was $133.63 \pm 26.66(\mathrm{z}=10.62$, p-value=0.000). Mean LVMI for patients with LVH was $138.06 \pm 27.52$ and that for without LVH was $81.74 \pm 13.08(\mathrm{z}=12.49$, p-value $=0.000)$. 
Co-Relation Of 24 Hours Proteinuria And Left Ventricular Hypertrophy In Hypertensive Patients.

Table 5: Logistic regression for LVH as a dependent variable and other factors are independent variable

\begin{tabular}{|c|c|c|c|}
\hline & Odd's Ratio & $\mathbf{T}$ & p-value \\
\hline $\mathrm{LVH}$ & & 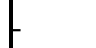 & - \\
\hline Age(yrs) & 0.109 & 1.24 & $0.218 \mathrm{NS}, \mathrm{p}>0.05$ \\
\hline Gender & 0.129 & 1.285 & $0.202 \mathrm{NS}, \mathrm{p}>0.05$ \\
\hline $\mathrm{BMI}\left(\mathrm{kg} / \mathrm{m}^{2}\right)$ & 0.046 & 0.45 & $0.652 \mathrm{NS}, \mathrm{p}>0.05$ \\
\hline BSA & 0.018 & 0.17 & $0.860 \mathrm{NS}, \mathrm{p}>0.05$ \\
\hline $\mathrm{SBP}(\mathrm{mmHg})$ & 0.308 & 2.74 & $0.007 \mathrm{~S}, \mathrm{p}<0.05$ \\
\hline $\mathrm{DBP}(\mathrm{mmHg})$ & 0.282 & 2.84 & $0.006 \mathrm{~s}, \mathrm{p}<0.05$ \\
\hline Retinopathy & 0.135 & 1.52 & $0.131 \quad \mathrm{NS}, \mathrm{p}>0.05$ \\
\hline Duration & 0.034 & 0.29 & $0.767 \mathrm{NS}, \mathrm{p}>0.05$ \\
\hline
\end{tabular}

Using multiple logistic regression analysis, SBP $(\mathrm{OR}=2.74$, $\mathrm{p}$-value=0.007) and DBP $(\mathrm{OR}=2.84$, $\mathrm{p}$ value $=0.006$ ) was significantly correlated with $\mathrm{LVH}$ and other parameters are not associated with $\mathrm{LVH}$.

Table 6: Logistic regression for proteinuria as a dependent variable and other factors are independent variable

\begin{tabular}{|l|l|l|l|}
\hline & Odd's Ratio & T & p-value \\
\hline Proteinuria & & & \\
\hline Age(yrs) & 0.019 & 0.235 & $0.815 \mathrm{NS}, \mathrm{p}>0.05$ \\
\hline Gender & 0.171 & 1.714 & $0.090 \mathrm{NS}, \mathrm{p}>0.05$ \\
\hline BMI(kg/m2) & 0.010 & 0.106 & $0.916 \mathrm{NS}, \mathrm{p}>0.05$ \\
\hline BSA & 0.116 & 1.261 & $0.211 \mathrm{NS}, \mathrm{p}>0.05$ \\
\hline SBP(mmHg) & 0.008 & 0.073 & $0.942 \mathrm{NS}, \mathrm{p}>0.05$ \\
\hline DBP(mmHg) & 0.070 & 0.742 & $0.460 \mathrm{NS}, \mathrm{p}>0.05$ \\
\hline Retinopathy & 0.379 & 3.662 & $0.000 \mathrm{~S}, \mathrm{p}<0.05$ \\
\hline Duration & 0.310 & 2.974 & $0.004 \mathrm{~S}, \mathrm{p}<0.05$ \\
\hline
\end{tabular}

Duration $(\mathrm{OR}=0.310, \mathrm{p}$-value $=0.004)$ and retinopathy $(\mathrm{OR}=0.379$, $\mathrm{p}$-value $=0.000)$ is significantly correlated with proteinuria by using multiple logistic regression analysis. 


\section{Discussion}

A total of 100 patients included in the study out of which 49 cases were male and 51 patients were female. In the present study 38 male and 47 female subjects were with left ventricular hypertrophy while 11 male and 4 female were without left ventricular hypertrophy. This was found to be statistically significant. Mean subject age, weight and BMI were not statistically significant. But these factors found to have role as seen in following studies.

Gender differences in left ventricular mass are first noticed around puberty. Women have been shown to have an increased parietal hypertrophic response to pressure overload, even after body size correction (Murilo foppa et al, 2005). ${ }^{(14)}$ Recent reports indicate that the prognostic implications of left ventricular hypertrophy (LVH) are more profound in women than in men. Study by Kuch B et al, 1998 may help to explain the higher risk associated with LVH in women. ${ }^{(15)}$

BMI has been shown to be independently associated to left ventricular hypertrophy and as a part of metabolic syndrome. Iacobellis et al, $\mathbf{2 0 0 2}$ have demonstrated that uncomplicated obesity was not a risk factor for left ventricular hypertrophy. As obesity decided by high BMI, when causes complications, it is frequently accompanied by additional risk factors. ${ }^{(16)}$

Left ventricular mass progressively increases with aging, particularly parietal thickness, which was seen in both normotensive and hypertensive patients. Dannenberg et al, 1989 demonstrated that Left ventricular mass did not increase with age in a healthy sub-sample of The Framingham study, suggesting that most of the supposed physiological increase is caused by other determinants. ${ }^{(17)}$

In this study, the high systolic and diastolic blood pressures are cause of left ventricular hypertrophy. The prevalence of left ventricular hypertrophy rises with severity of hypertension (Ruilope LM et al). ${ }^{(\mathbf{1 8})}$ Left ventricular hypertrophy has been associated with an increased risk of Left ventricular dysfunction(Meijs et al,2007). ${ }^{(19)}$ Verdecchia $\mathbf{P}$ et $\mathbf{a l ( 2 0 0 3 )}$ concluded that regression of left ventricular hypertrophy during antihypertensive treatment is associated with a marked reduction in risk for subsequent cardiovascular disease. ${ }^{(20)}$

In this study the hypertension is significantly correlated with proteinuria. It has been suggested by Albert Mimram et al that the proteinuria especially microalbuminuria can be a marker of early intrarenal vascular dysfunction in essential hypertension. ${ }^{(21)}$ S.Jalal et al (2001) determined the frequency of increased urinary albumin excretion (UAE) in essential hypertension. ${ }^{(22)}$

In the present study, left ventricular hypertrophy is significantly related with proteinuria. In study by $\mathbf{G}$. Dell'omo et al(2003) and Mahfoud $\mathbf{F}$ et al(2012) the risk of microalbuminuria increased linearly by ascending quartiles of LVMI and was 2.3-fold higher in the presence of left ventricular hypertrophy after adjustment for age, left atrial size, mean fractional shortening. ${ }^{(23)(24)}$

According to Forlemu et al (2013), Urinary Protein Excretion Is Associated with left ventricular hypertrophy in untreated hypertensive patients in an African Hospital Setting. ${ }^{(9)}$

Saitoh M et al (1998) noted that the incidences of proteinuria and advanced retinal vascular change were higher in patients with left ventricular hypertrophy than in those without left ventricular hypertrophy and concluded that proteinuria is related to elevated left ventricular mass in patients with essential hypertension. ${ }^{(25)}$

According to estimates from Framingham study, Sheshadri et al concluded that blood pressure is significant determinant for life time risk of stroke. ${ }^{(26)}$

It has been mentioned in studies by Wolf et al and Wachtell et al that the increasing levels of microalbuminuria were associated with increasing risks for heart attacks and strokes. Risk continuously increases in a linear manner. ${ }^{(27)(28)}$

In this study, the proteinuria is significant when associated retinopathy is present. Similar finding was seen in a study by S. Mokoto et al. ${ }^{(25)}$ They noted that the incidences of proteinuria and advanced retinal changes are significant.

In the present study there was significant difference in the left ventricular geometry (like LVIDD, PWTD, IVSTD) of subjects when the left ventricular hypertrophy was present.

Pontremoli et al studied the Left ventricular geometry and function in patients with essential hypertension and microalbuminuria. Hypertensive patients with microalbuminuria show a higher prevalence of unfavourable left ventricular geometric patterns, depressed left ventricular function and early signs of extracardiac vascular damage. ${ }^{(29)}$

In our study, logistic regression analysis was done for left ventricular hypertrophy to evaluate for risk factors. The systolic and diastolic blood pressures were related significantly.

The positive linear relationship between SBP and DBP and cardiovascular risk has long been recognized (I.G.H. III, 2013). ${ }^{(30)}$

The logistic regression analysis was also done for proteinuria to evaluate for risk factors. The retinopathies, duration of illness were related significantly. 
In this study significant positive correlation was found between proteinuria and left ventricular hypertrophy which means that as left ventricular hypertrophy increases proteinuria also increases significantly.

These similar findings seen following study by Poudyal $\mathbf{N}$ et al(2010). In patients with hypertension, left ventricular hypertrophy was associated with increased prevalence of microalbuminuria compared to patients without left ventricular hypertrophy. ${ }^{(8)}$

Mettimano et al (2001) evaluated the prevalence of Urinary albumin excretion in hypertension with normal left ventricular mass and studied association with blood pressure level as well as any modification in left heart function. They concluded urinary albumin excretion is associated with subclinical decrease of left ventricular function and may be early marker of cardiac involvement. ${ }^{(31)}$

Pontremoli $R$ et al (1998) concluded that microalbuminuria correlates with cardiovascular risk factors commonly associated with hypertension and is early marker of diffuse target organ damage in essential hypertension. ${ }^{(32)}$

C Cuspidi et al(2005), Mule $G$ et al(2005) and Mokoto $S$ et al(1998) directly implicated the hypertension in target organ damage causing left ventricular hypertrophy, large artery and microvascular disease leading to atherosclerosis, retinopathy and proteinuria. ${ }^{(33)(34)(25)}$

In this study, the high systolic and diastolic blood pressures are cause of left ventricular hypertrophy. The hypertension progressively causes left ventricular enlargement leading to systolic and diastolic dysfunction The hypertension over a period of time causes renal damage in the form of proteinuria. The proteinuria and left ventricular hypertrophy are significantly correlated with each other. The findings in this study point toward the role of proteinuria in the development of retinopathy.

\section{Conclusion}

The hypertension systolic and diastolic both have causative role in development of left ventricular hypertrophy. The left ventricular hypertrophy is more common in females. Hypertensive subjects develop proteinuria. As duration of hypertension increases, left ventricular hypertrophy and proteinuria also increases. The hypertensive patients are at risk of developing target organ damage viz, left ventricular hypertrophy, proteinuria, retinopathy.

\section{Refernces}

[1]. Kuan Huei Nq, Adrian GS, Williams B. Hypertension. Medicine, 2010; 38(8):403-408

[2]. Nahla KRI, Hijazi NA, Al-Bar AA. Prevalence and determinants of Prehypertension and Hypertension among Preparatory and Secondary School Teachers in Jeddah. J Egypt Public Health Assoc, 2008; 83(3) (4): 183-203.

[3]. Patricia MK, Whelton M, Reynolds K, Muntner P, Whelton PK, He J. Global Burden of Hypertension: analysis of Worldwide Data. The Lancet, 2005 Jan; 365(9455):217-223.

[4]. Patricia MK, Whelton M, Reynolds K, Whelton PK, He J. Worldwide Prevalence of Hypertension: a systemic review. J Hypertens, 2004 Jan: 22(1):11-19.

[5]. Chobania AV, Bakris GL, Black HR, Cushman WC, Green LA, Izzo Jr JL et al. Seventh report of Joint National Committee on Prevention, Detection, Evaluation and Treatment of high blood pressure. Hypertension.2003 Dec 1; 42: 1206-1252.

[6]. Chobanian AV, Bakris GL, Black HR, Cushman WC, Green LA, Izzo JL Jr et al. Seventh report of Joint National Committee on Prevention, Detection, Evaluation and Treatment of high blood pressure: JNC 7 Report. JAMA, 2003 Jul 9; $290(2): 197$.

[7]. Modesti PA, Bamoshmoosh M, Rapi S, Massetti L, Bianchi S, Al-Hidabi D et al. Relationship between hypertension, diabetes and proteinuria in rural and urban households in Yemen. J Hum Hypertens, 2013; 27:572-579.

[8]. Poudyal N, Rana JK, Srivastava B, Karki B, Basnet B. Frequency of microalbuminuria in hypertensive patients with left ventricular hypertrophy. PMJN, 2010;10(2):41-44

[9]. Forlemu A, Menanga A, Ashuntantang G, Kingue S. Urinary protein excretion is associated with left ventricular hypertrophy in treatment Naïve hypertensive patients in an African hospital setting. Cardiorenal Med, 2013; 3:57-62.

[10]. VK Paul Ghai OP, Jain V. Normal growth and its disorders. In:Ghai OP, Bagga A, Paul VK, editors. Ghai Essential Pediatrics. 7th ed. New Delhi: CBS Publishers \& Distributors; 2009. p. 1-21

[11]. Kashif W, Siddiqi N, Dincer AP, Dincer HE, Hirsch S. Proteinuria: How to evaluate an important finding? Cleve Clin J Med, 2003 Jun; 70(6):535-7,541-44,546-7.

[12]. Devereux RB, Alonso DR, Lutas EM, Gottlieb GJ, Campo E, Sachs I, et al. Echocardiographic assessment of left ventricular hypertrophy: comparison to necropsy findings. Am J Cardiol 1986, 57:450-458.

[13]. Connolly HM, Koh J. Echocardiography. Bonow RO, Mann DL, Zipes DP, Libby P. Brawnwald heart disease: Text book of cardiovascular medicine, $9^{\text {th }}$ ed, New Delhi, Elsevier; 2012. p.-216.

[14]. Foppa M, Duncan B Band Luis, Rohde LEP. Echocardiography- based left ventricular mass estimation. How should we define hypertrophy? Cardiovascular Ultrasound 2005, 3:17.

[15]. Kuch B, Muscholl M, Luchner A, Döring A, Riegger GA, Schunkert H, et al.Gender specific differences in left ventricular adaptation to obesity and hypertension. J Hum Hypertens. 1998; 12(10):685-91.

[16]. Iacobellis G, Ribaudo MC, leto G, Zappaterreno A, Vecci E, Di Mario U. Influence of excess fat on cardiac morphology and function: Study in uncomplicated obesity. Obes res. 2002; 10 (8):767-73.

[17]. Andrew L. Dannenberg AL. Impact of age on echocardiographic left ventricular mass in a healthy population (the Framingham study) Am J Cardiol 64, 16: 1066-1068.

[18]. Ruilope LM Schmieder RE. Left ventricular hypertrophy and clinical outcomes in hypertensive patients. Am J Hypertens. 2008; 21 (5):500-8

[19]. Meijs MF, Bots ML, Vonken EJ , Cramer MJ, Melman PG, Velthuis BK, et al. Rationale and design of Smart Heart Study: A prediction model for left ventricular hypertrophy in hypertension. Neth Heart J, 2007 Sep; 15(9):295-298

[20]. Verdecchia P. Prognostic value of ambulatory blood pressure: Current evidence and clinical implications. Hypertension, 2000; 
35: 844-851.

[21]. Mimran A, Ribstein J, DuCailar G. Is microalbuminuria a marker of early intrarenal vascular dysfunction in essential? Hypertension. 1994; 23:1018-1021.

[22]. Jalal S, Sofi FA, Alai MS, Sidiqqi MA, Bhat MA, Khan KA. Prevalence of microalbuminuria in essential hypertension: A study of patient with mild to moderate hypertension. Indian J Nephrol, 2001; 11:6-11.

[23]. Dell'omo G, Giorgi D, Di Bello V, Mariani M and Pedrinelli R. Blood pressure independent association of microalbuminuria and left ventricular hypertrophy in hypertensive men. J Intern Med. 2003; 254:76-84.

[24]. Mahfoud F, Ukena C, Pöss J, Bramlage P, Volpe M, Thoenes M, et al. Microalbuminuria independently correlates to cardiovascular comorbidity burden in patients with hypertension. Clin Res Cardiol. 2012; 101(9):761-6.

[25]. Saitoh M, Matsuo K, Nomoto S, Kondoh T, Yanagawa T, Yasuchika Katoh Y, et al. Relationship between left ventricular hypertrophy and renal and retinal damage in untreated patients with essential hypertension. J Intern Med. 1998; 37: 576-580.

[26]. Seshadri S, Beiser A, Kelly-Hayes M, Carlos S, Kase S, Au R, et al. The Lifetime risk of stroke: Estimates from the Framingham study. Stroke. 2006; 37:345-350.

[27]. Wolf PA, R B D'Agostino RB, Belanger AJ and Kanne KB. Probability of stroke: a risk profile from the Framingham Study. Stroke. $1991 ; 22: 312-3186$.

[28]. Wachtell K, Ibsen H, Olsen MH, Borch-Johnsen K, Lindholm LH, C.E. Mogensen et al. Microalbuminuria increases risk for heart attacks and strokes in hypertensive patient. Ann Intern Med, 2003; 139: 901-90.

[29]. Pontremoli R, Maura R, Paolo BG, Francesca V, Clizia N, Valeria B, et al. Left ventricular geometry and function in patients with essential hypertension and microalbuminuria. J Hypertense 1999; 17(7):993-1000.

[30]. Shah SN. Indian Guidelines on Hypertension-III-2013.JAPI. 2013 Feb; 61(2).

[31]. Mettimano M, Specchia ML, Migneco A, Savi L. Microalbuminuria as a marker of cardiac damage in essential hypertension. Eur Rev Med Pharmacol Sci, 2001; 5:31-36.

[32]. Pontremoli R, Nicolella C, Viazzi F, Ravera M, Sofia A, Berruti V, et al. Microalbuminuria is an early marker of target organ damage in essential hypertension. Am J Hypertens, 1998 Apr; 11(4 Pt 1):430:8.

[33]. Cuspidi C, Meani S, Fusi V, Valerio C, Catini E, Magrini F, et al. Isolated ambulatory hypertension and changes in target organ damage in treated hypertensive patients. J Hum Hypertens. 2005; 19(6):471-7.

[34]. Mule G, Nardi E, Cottone S, Cusimano P, Volpe V, Piazza G, et al. Influence of metabolic syndrome on hypertension- retaliated target organ damage. J Intern Med. 2005; 257:503-513.

\section{Cover Letter}

This research work focuses on the morbidity caused by hypertension in the form of target organ damage. It tends to find out the correlation between 24 hours proteinuria and left ventricular hypertrophy in patients of hypertension. The data was collected from In- patient department. 